\title{
The Value of Impact-Based Decision Support Services \\ Case Studies with Winter Storms
}

\author{
Adapted from "Impact-Based \\ Decision Support Services and \\ the Socioeconomic Impacts \\ of Winter Storms," by Jeffrey \\ K. Lazo (Jeffrey K. Lazo \\ Consulting, LLC), Heather \\ R. Hosterman, Jennifer M. \\ Sprague-Hilderbrand, and \\ Jeffery E. Adkins. Published \\ online in BAMS, May 2020. \\ For the full, citable article, see \\ DOI:10.1175/BAMS-D-18-0153.1.
}

n 2011, the National Weather Service (NWS) formalized their approach to impact-based decision support services (IDSS). IDSS better connects forecasts and warnings to critical decisions of core partners who prepare and disseminate weather, water, or climate information to protect lives and livelihoods. It is part of NWS efforts to build a Weather-Ready Nation, where communities are ready, responsive, and resilient with respect to increasing vulnerabilities from extreme weather, water, and climate, as well as environmental hazards.

IDSS builds on the basic services that NWS provides to general partners and the public, including provision of general forecasts/ warnings, response to calls from the public, education about NWS data/products, and outreach/interaction for preparedness. Through IDSS, NWS can tailor services to a core partner based on situation and need. NWS Core Partners are defined as "government and non-government entities which are directly involved in the preparation, dissemination, and discussions involving weather, water, or climate related National Weather Service information that supports decision making for routine or episodic high impact events.” Some IDSS are provided for ongoing weather events, while others are provided on an ongoing basis.

We believe that formal IDSS provides better information and support for reducing socioeconomic impacts during extreme winter storms. To evaluate this, we compared the socioeconomic impacts of two storms in the New York City (NYC) area: one storm before the implementation of formal IDSS and another 
afterward. One of the objectives of this project is to provide a foundation for valuing benefits associated with IDSS, showing how IDSS can improve decision-making outcomes associated with the use of weather forecast information.

\section{Measuring socioeconomic impacts of IDSS}

We developed a conceptual model of how IDSS works and how it can benefit decision-makers. In this model, prestorm weather is observed and modeled, leading to forecasts and warnings. IDSS enables additional capabilities and procedures beyond dissemination and communication of forecasts and warnings through conventional channels to better connect forecasts and warnings to the decision process in a collaborative way, ensuring the information is more relevant to and more accurately understood by decision-makers.

We expect that IDSS leads to more proactive decision-making by core partners to help reduce social and economic impacts of storms. The question is, what is the magnitude of the difference in observed impacts in monetary or other socioeconomic measures with and without IDSS? As our study shows, this difference can be taken as the benefits of IDSS.



* Value chain of IDSS information. With the
advent of the NWS IDSS, additional capabilities
and procedures are implemented to improve the
dissemination and communication of forecasts
and warnings to core partners to ensure the
information is more relevant to decision-makers
to enhance the protection of property and
health and safety.

To begin to evaluate the benefits of IDSS, we used a case study approach to characterize the differences in decision processes and impacts between two storms with similar characteristics but differing in their implementation

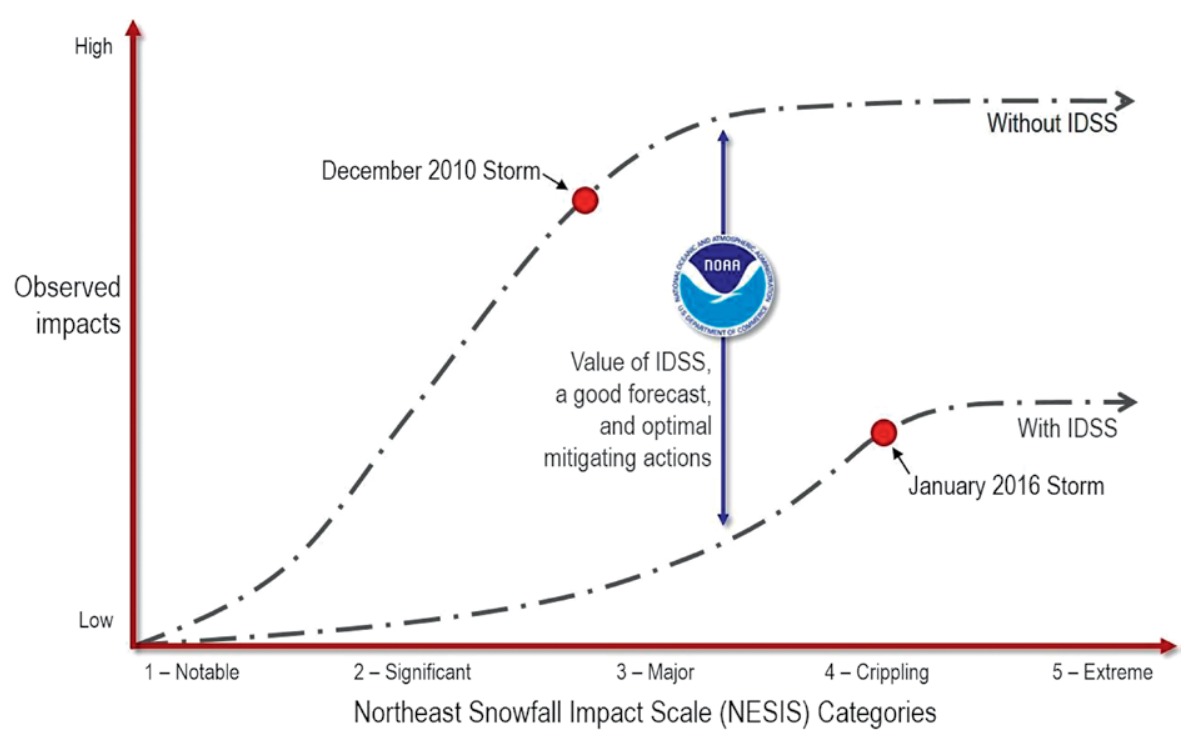

4 * Conceptual model on the value of IDSS (not drawn to scale). The Northeast Snowfall Impact Scale (NESIS) is based on the storm magnitude and population affected. The curves reflect the presumption that damage is less with IDSS adequately implemented and show larger differences for major storms where improved decision-making from IDSS may maximize societal benefits, but differences level off for extreme storms in which improved decision-making cannot prevent many impacts. 
of IDSS: a December 2010 storm without formal IDSS and a January 2016 storm with formal IDSS. We gathered data and interviewed experts from several agencies and organizations, including forecasters, emergency managers, and decision-makers in the aviation, ground transportation, and energy sectors. To monetize aviation impacts, we used Bureau of Transportation Statistics data to estimate the number of flight cancellations due to each storm. We then estimated the cost of flight cancellations to airlines and airline passengers separately. For the energy sector, we used data from local utilities to estimate the number of customers whose service was interrupted from power outages and the power outage duration. For ground transportation, we elicited information on storm impacts on roadways and public transportation (buses, subways, and rail) and poststorm recovery times. Where feasible, we then monetized the cost to customers, accounting for societal changes between the two storms.

\section{December 2010 storm}

The large Northeast blizzard of 25-27 December 2010 first appeared in the NWS Hazardous Weather Outlook on 21 December, but the forecasts had much uncertainty and subsequent day-to-day challenges. While early forecasts predicted light-to-moderate snowfall, on 24 December, models suddenly converged and indicated heavy snow for the NYC area on 26 December. By 25 December, confidence grew that NYC would indeed experience a major winter storm, and a blizzard warning issued later that afternoon predicted 11-16 inches of snow.

Snow fell at 1-2 inches per hour, accumulating 20-30 inches across NYC and the Lower Hudson Valley and 10-20 inches across Long Island. Winds gusted $30-45 \mathrm{mph}$, occasionally exceeding $60 \mathrm{mph}$.

Forecast uncertainty limited storm preparations until just before the onset of the storm, and this uncertainty was compounded by having to bring road crews and other city workers into work on Christmas Eve and Christmas Day. Many of the more than 3,030 pieces of snow removal equipment deployed by NYC agencies were not properly equipped, and the city did not ensure that sufficient private contractors were on call. NYC decided against declaring a snow emergency and did not issue other hazardous weather advisories, because for days the storm was forecast to just miss the NYC area. Mitigation was largely reactive and often hampered by the lack of preparation. Although IDSS was not formalized in 2010, the New York Weather Forecast

\begin{tabular}{|c|c|c|}
\hline & December 2010 & January 2016 \\
\hline \multirow[t]{6}{*}{ IDSS } & Informal IDSS & Formal IDSS \\
\hline & $\begin{array}{l}\text { Remote IDSS using emails, phone conversations, and } \\
\text { WebEx }\end{array}$ & $\begin{array}{l}\text { Briefings to emergency managers, serviced media requests, } \\
\text { and answered spotter calls from Saturday, } 16 \text { January, } \\
\text { through Tuesday, } 26 \text { January }\end{array}$ \\
\hline & Live webinar for additional visibility & $\begin{array}{l}\text { Executive-level conference calls with Governor Christie, } \\
\text { Governor Cuomo, and Mayor de Blasio }\end{array}$ \\
\hline & & $\begin{array}{l}\text { Email briefings to coastal partners on coastal flooding } \\
\text { hazards and impacts }\end{array}$ \\
\hline & & $\begin{array}{l}\text { "High-impact" summary email to aviation partners that } \\
\text { highlighted potential snowfall and indicated surface travel } \\
\text { issues for airport employees }\end{array}$ \\
\hline & & Public outreach via social media \\
\hline \multirow{4}{*}{$\begin{array}{l}\text { Mitigating } \\
\text { Actions }\end{array}$} & No hazardous weather advisory issued & Hazardous weather advisory issued \\
\hline & $\begin{array}{l}\text { No prohibition of standing or parking a vehicle on snow } \\
\text { emergency streets; no chain or snow tire requirements } \\
\text { when driving on snow emergency streets }\end{array}$ & $\begin{array}{l}\text { Citywide travel ban issued; prohibition of standing or } \\
\text { parking a vehicle on snow emergency streets; chain or snow } \\
\text { tire requirements when driving on snow emergency streets. }\end{array}$ \\
\hline & $\begin{array}{l}\text { Delayed snow removal in NYC; NYC deployed 3,030 } \\
\text { snow-removal vehicles }\end{array}$ & NYC deployed 3,990 snow-removal vehicles \\
\hline & & Shut down NYC \\
\hline
\end{tabular}


Office (WFO) provided informal offsite IDSS using emails, phone calls, and WebEx. As the storm forecasts showed a strengthening storm, the WFO hosted a live webinar for additional visibility.

\section{January 2016 storm}

A record-breaking storm on 22-25 January 2016 dropped heavy snow from Louisiana to Maine. It first appeared in the NWS Hazardous Weather Outlook on 18 January, with high certainty of impacts in the mid-Atlantic region. However, the NYC area was outside of the forecasted high-impact area. On the morning of 21 January, NWS issued the first blizzard and winter storm watches. Forecasts put NYC in the high-impact area only one day ahead. On 23 January, the severity of the forecast was upgraded to blizzard warnings with predicted snowfall between 24 and 28 inches in the NYC area.

Snow accumulations in the NYC area were 20-30 inches, and Central Park's 27.5 inches was its greatest total since 1869. Winds gusted to $50 \mathrm{mph}$. The storm also caused widespread erosion and local coastal flooding.

Like the December 2010 storm, the forecast for the severity of the weather was upgraded just before the storm struck NYC. However, unlike the December 2010 storm, the provision of IDSS began a week before the storm's onset, with telephone briefings to New York City Emergency Management (NYCEM) that lasted into early the following week during recovery efforts. The NWS provided weather briefings, serviced media requests, answered spotter calls, and provided separate email briefings on coastal flooding hazards and impacts as well as on potential snowfall and disruptions for airport employees. NWS staff also participated in executive-level conference calls with Governors Christie and Cuomo and Mayor de Blasio. Furthermore, embedded in the NYC Emergency Operations Center (EOC), NWS meteorologists provided onsite IDSS from 22 January to 24 January.

As state, city, and local government agencies issued several advisories and actions to reduce storm impacts, NWS continued to provide extensive, formal IDSS activities, especially within the various EOCs where they remained onsite. This was made possible by the trust NWS had built with NYCEM and other local partners over the preceding five years by providing and refining IDSS offerings and participation in various tabletop exercises led by the emergency management community.

\begin{tabular}{|c|c|c|c|c|}
\hline Sectors & $\begin{array}{c}\text { Social and economic impact } \\
\text { category }\end{array}$ & December 2010 & January 2016 & Improvement \\
\hline \multirow[t]{3}{*}{ Aviation } & $\begin{array}{l}\text { Number of flight cancellations due to } \\
\text { weather }\end{array}$ & $3,760(50.2 \%)$ & $2,420(40.1 \%)$ & - \\
\hline & Recovery time (days) & 3 & 3 & 0 \\
\hline & $\begin{array}{l}\text { Costs to airlines and customers } \\
\text { (millions of USD 2016) }\end{array}$ & $20.5+40.3=60.8$ & $13.2+30.1=43.3$ & $\$ 17.5^{a}$ \\
\hline \multirow[t]{5}{*}{$\begin{array}{l}\text { Ground } \\
\text { transportation }\end{array}$} & Roadways & $\begin{array}{l}\text { Severe road blocks with } \\
\text { disabled vehicles }\end{array}$ & $\begin{array}{l}\text { Proactively closed to } \\
\text { nonessential vehicles }\end{array}$ & \multirow[t]{4}{*}{$\begin{array}{l}\text { Reactive to } \\
\text { proactive }\end{array}$} \\
\hline & Buses & Delays & $\begin{array}{l}\text { Proactive service } \\
\text { suspension }\end{array}$ & \\
\hline & Subways & Delays & $\begin{array}{l}\text { Proactive service } \\
\text { suspension }\end{array}$ & \\
\hline & Rail & $\begin{array}{l}\text { Reactive service } \\
\text { suspension }\end{array}$ & $\begin{array}{l}\text { Proactive service } \\
\text { suspension }\end{array}$ & \\
\hline & Recovery time (days) & 7 & 2 & 5 \\
\hline \multirow[t]{3}{*}{ Energy } & $\begin{array}{l}\text { Number of customers with power } \\
\text { outages }\end{array}$ & 76,930 & 30,690 & 46,230 \\
\hline & Average duration of power outages (h) & 12.2 & 4.8 & 7.4 \\
\hline & $\begin{array}{l}\text { Estimated average electric customer } \\
\text { interruption cost (millions of USD 2016) }\end{array}$ & $\$ 106.8$ & $\$ 14.7$ & $\$ 92.1$ \\
\hline
\end{tabular}

\footnotetext{
a Improvement is based on 2010 and 2016 flight weighted impacts as described in the text.
} 


\section{Impacts and benefits}

Examining the differences in impacts of the December 2010 winter storm (without formal IDSS) and January 2016 winter storm (with formal IDSS) is an indication of the value of IDSS, acknowledging that there are several other factors leading to differences in impacts.

During the December 2010 storm, there were widespread flight cancellations and delays due largely to a reactive approach by many airlines. Approximately 3,760 flight cancellations due to weather cost airlines $\$ 20.5$ million and passengers \$40.3 million. During the January 2016 storm, airports also experienced extensive-but mostly more proactive-cancellations and delays. Approximately 2,420 flight cancelations due to weather cost airlines $\$ 13.2$ million and passengers $\$ 30.1$ million. This indicates that IDSS, along with proactive decision-making, provided a potential benefit of approximately $\$ 17.5$ million between these two eventsor approximately $\$ 35.3$ million for a typical winter in the NYC area.

Ground transportation impacts during the 2010 storm were significantly greater than during the 2016 storm. The reactive response in 2010 was largely ineffective, and public transportation was severely hampered, with resulting delays and interruptions. The quicker snow removal and other actions in 2016 included proactive suspension of bus, subway, and railroad services, reducing the number of vehicles that were immobilized by the storm and obstructing recovery actions. This meant fewer delays and reduced recovery time for ground transportation from 7 to 2 days.

The storm in 2016 also saw interruption costs of energy provision to customers reduced by more than $\$ 92.1$ million. The regional utility had made significant investments in storm hardening after Hurricane Sandy in 2012, which likely reduced power outages. However, we believe that IDSS also likely contributed to this decrease.

\section{Discussion}

The purpose of this study was to explore methods to qualitatively and quantitatively assess the socioeconomic benefits of IDSS and lay the groundwork for future studies to further assess IDSS. Using a case study comparison of two extreme winter storms in the NYC region, we find strong indications that IDSS has

\section{- For further reading}

For more information about IDSS, see the NWS Service Description Document (SDD) ImpactBased Decision Support Services for NWS Core Partners, April 2018 (www.nws.noaa.gov/im /IDSS_SDD_V1_0.pdf).

Foracompanionarticlepleasesee:Hosterman, H. R., J. K. Lazo, J. M. Sprague-Hilderbrand, and J. E. Adkins, 2019: Using the National Weather Service's impact-based decision support services to prepare for extreme winter storms. J. Emerg. Manage., 17, 455-467, DOI:10.5055/jem. 2019 .0439 .

improved decision-making, enhanced communication between the NWS and core partners, and reduced societal and economic impacts of extreme winter weather events.

The uncertainty ranges in our benefit estimates are likely significant, but we think the estimates are of the correct sign and nonzero. And with sectors highly interdependent, that IDSS reduced impacts in aviation, ground transportation, and the energy sector means they likely provided significant benefits to virtually every other sector in the NYC region as well. Some improvements in outcomes are due to other preparations, capacities, and processes.

To build a stronger business case for IDSS, we recommend more case studies to control for differences in storms, forecasts, and societal and institutional changes between storms. We would prefer a larger dataset over time, but extreme events are few and far between and diverse socioeconomic influences are difficult to measure. To move in that direction, we recommend examining the implementation of IDSS for hurricanes, tornadoes, floods, and droughts, as well. We also recommend integrating case study results into the IDSS process, collecting information during each extreme event. While this is a complex challenge, it is necessary to solidify the connections between the weather community and those making decisions to protect life and property. $\therefore$ 


\section{Be prepared, not scared.}

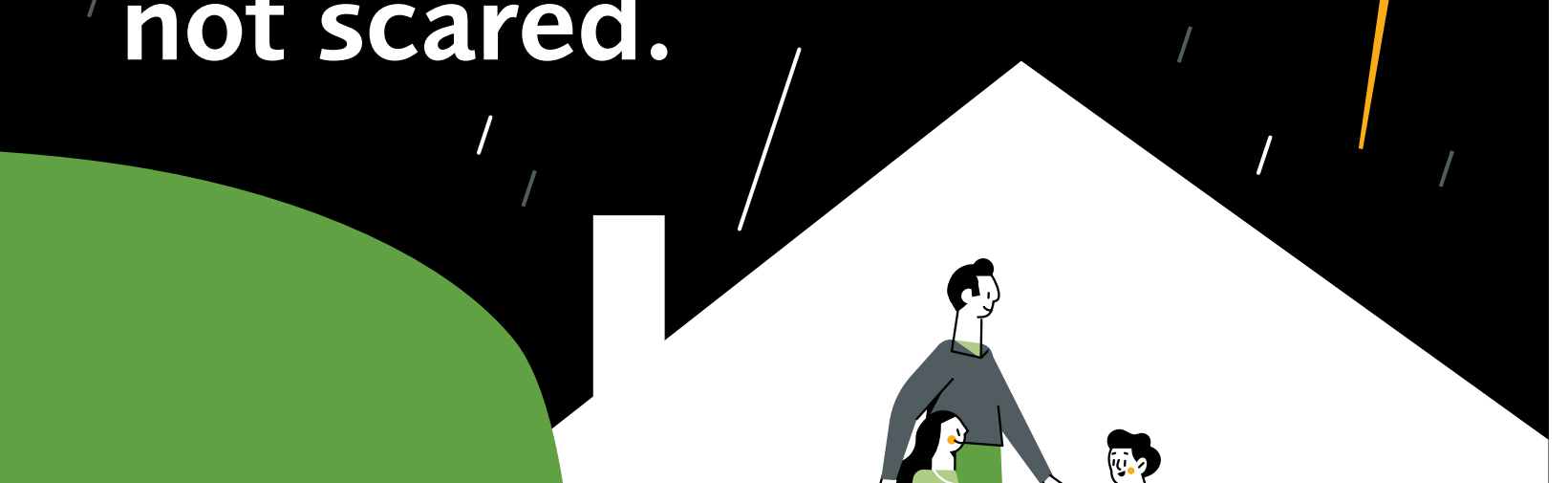

Considering the number of disasters that have occurred in the past decade, chances are you'll experience some sort of emergency. Between school, sports and other activities, chances are you won't be with your kids when it happens.

Ready.gov/kids has the tools to make preparing easy and even fun, so your kids can feel...

Prepared, not scared.

\section{Go to \\ www.Ready.gov/kids}

and talk to your family today.

ad Ready. FEMA 